\title{
EFEITOS DA COMUNICAÇÃO NO CICLO DE VIDA DE UM PROJETO DE ENGENHARIA
}

\section{EFFECTS OF COMMUNICATION ON THE LIFE CYCLE OF AN ENGINEERING PROJECT}

\author{
Anderson de Farias Alves \\ Acadêmico do $10^{\circ}$ período do Curso de Engenharia Civil da Faculdade Presidente \\ Antônio Carlos de Teófilo Otoni. \\ E-mail: andersonfariastecnologo@gmail.com
}

\begin{abstract}
Danilo Carvalho Miranda
Especialista em Gestão de Negócios e Finanças; Graduado em AdministraçãoProfessor dos Cursos de Administração e Engenharia Civil (FUPAC-TO)

E-mail: danilocarvalho.unipacto@hotmail.com
\end{abstract}

\section{Resumo}

Este artigo analisa fatores intrínsecos à comunicação no ciclo de vida de um projeto de Engenharia Civil demonstrando a influência daquela quando aplicada no cotidiano. A ideia principal está relacionada ao questionamento sobre a sua importância e os seus efeitos dentro da organização, em que frequentemente existem falhas e geração de ruídos por não haver fluidez no compartilhamento das informações entre as partes interessadas e diretamente ligadas ao projeto. É abordado neste artigo as ferramentas e os canais de comunicação mais utilizados pelas organizações realizando um estudo de caso comparativo entre duas empresas de engenharia civil da cidade de Teófilo Otoni analisando a empregabilidade das ferramentas e canais de comunicação em 5 quesitos. Tais quesitos são: Comunicação com o Cliente; Comunicação no Canteiro de Obras; Comunicação no Ambiente de Suporte à Produção; Comunicação entre Suporte à Produção e Canteiro de Obras; Comunicação com Fornecedores. Com a globalização e avanço tecnológico, as empresas do setor de engenharia vem se adaptando e se moldando a uma nova forma de comunicação para que os colaboradores estejam bem informados e contextualizados do atual cenário das empresas.

Palavras-chave: Comunicação Interna; Ferramentas e Canais; Ciclo de Vida; Partes Interessadas.

\section{Abstract}

This paper analyzes the intrinsic factors of communication in the life cycle of a Civil Engineering project demonstrating the influence of that when applied in daily life. The main idea is related to the questioning of its importance and its effects within the organization, where there are often failures and noise generation due to lack of fluidity in the sharing of information between the interested parts and directly linked to the project. This article discusses the tools and communication channels most used by the organizations conducting a comparative case study between two civil engineering companies in the city of Teófilo Otoni analyzing the employability of tools and communication channels in 
5 questions. These are: Communication with the Customer; Communication at the Construction Site; Communication in the Production Support Environment; Communication between Production Support and Construction Site; Communication with Suppliers. With globalization and technological advancement, companies in the engineering sector have been adapting and shaping a new form of communication so that employees are well informed and contextualized in the current business scenario.

Keywords: Internal communication; Tools and Channels; Life cycle; Interested parts

\section{Introdução}

Em face ao vertiginoso e competitivo desenvolvimento do setor da engenharia civil, houve-se também a necessidade de potencializar outra área de grande importância na cadeia produtiva da construção e principalmente nas relações de trabalho. Tal área estava sendo descuidada ou gerenciada inadequadamente, mas ainda hoje requer atenção especial, pois necessita constantemente de meios e recursos para torná-la cada vez mais fluida, clara e diligente: a comunicação entre as partes interessadas dentro do clico de vida de um projeto.

As falhas na comunicação, a ausência de engenharia integrada e a geração de ruídos provoca um distanciamento entre os elos de quem cria, quem executa, quem investe ou quem fornece serviços e projetos. Além disso, desencadeia numerosos retrabalhos, desperdícios e altos custos aos construtores e financiadores de vários empreendimentos, uma vez que os prazos de execução são substancialmente dilatados, até que se conclua a compatibilização, a compreensão e a contextualização de todos os processos e membros envolvidos. Somente a partir de então será possível realizar uma leitura fidedigna e um planejamento competente dos projetos, e consequentemente, uma produção/execução assertiva com qualidade, controle e economia.

Dessa forma, para que haja dentro de uma organização, especialmente na esfera da Construção Civil, um planejamento e gerenciamento minucioso, desde a concepção do projeto, até a aquisição de materiais e locação de equipamentos com baixos custos e rapidez, contratação de mão de obra acessível e qualificada, parcerias duradouras com prestadores de serviços que atendam de forma eficiente às demandas do projeto e boa logística técnica-gerencial, devem existir dentro do ciclo de vida de um projeto uma adequada comunicação entre as partes interessadas: os stakeholders, termo criado em 1963 pelo filósofo Robert 
Edward Freeman que faz referência a todo grupo ou indivíduo que influencia ou é influenciado pelo alcance dos objetivos da organização, ou seja, a pessoas ou grupos que estão relacionados ao projeto tais como gerentes, patrocinadores, equipes, clientes em questão, fornecedores e investidores.

Nesse sentido, a preocupação é, portanto, a busca de uma melhoria generalizada da produtividade com alto desempenho e a comunicação fluida na operacionalização dos serviços. Entretanto, esta última nem sempre foi reconhecida e valorizada com a devida importância para o desenvolvimento e sobrevivência das organizações. Em tempos em que a informação e a tecnologia são disponibilizadas de forma rápida, precisa e segura, a habilidade no processamento dessas informações e a transferência desses dados para as tomadas de decisões representa uma valiosa chance no avanço do processo de comunicação no mundo dos negócios, uma vez que só a partir da interação e comunicação efetiva, é que acontece a troca de informações, a aproximação entre os projetos organizacionais e sua plena execução (MELO, 2006).

Esta problemática também foi enfatizada por Ruggiero (2002) em seu artigo "Qualidade da Comunicação Interna", no qual foi destacado que de nada adiantaria ter uma equipe de grandes talentos altamente motivados, se ela não estiver bem informada e se seus integrantes não se comunicarem adequadamente, pois não seria possível potencializar a força humana da empresa.

Sob esta mesma perspectiva, Closs (2018) oferece à comunicação interna a importância de um 'Setor Organizacional', que necessita ser planejado e estruturado, com objetivos definidos para possibilitar a interação generosa e coletiva entre a organização e seus colaboradores. Para Closs (2018), com a comunicação eficaz é possível aprimorar os relacionamentos, aumentar a produtividade, ampliar o engajamento dos profissionais, agregando propósitos coletivos que influenciam diretamente na elevação dos resultados positivos financeiros de uma organização.

Baseando-se nessas premissas, o presente artigo tem por objetivo responder ao seguinte questionamento: Qual a importância e os efeitos da comunicação dentro de uma organização, em que frequentemente há falhas e geração de ruídos por não haver fluidez no compartilhamento das informações entre as partes interessadas e diretamente ligadas ao projeto, principalmente em projetos do setor da engenharia civil?

Assim, pretende-se com esse estudo, por meio de revisões bibliográficas, 
levantar importantes conceitos e analogias sobre o tema, com o objetivo de destacar a importância de uma adequada comunicação nas relações de trabalho, especialmente na esfera da Construção Civil, buscando meios de aprimorá-la e potencializá-la, para que se promova um novo olhar para esta área pouco discutida e para que, progressivamente, impulsione o desenvolvimento de um consistente elo de comunicação entre os stakeholders de um projeto.

\section{Revisão de Literatura}

\subsection{Definição de Comunicação}

A necessidade de se comunicar acompanha o surgimento e a evolução do ser humano, e desde aquela época comunicar-se é questão de sobrevivência, assim como em qualquer meio corporativo ou organização. A palavra comunicação é originária do latim communicare, que significa "tornar comum", "partilhar", "repartir", "associar", "trocar opiniões", "conferenciar". De acordo com Rabaça e Barbosa (1987) apud MATOS (2009), no livro "Dicionário de Comunicação", comunicar implica em participação (communicatio tem o sentido de "participação"), interação, troca de mensagens, emissão ou recebimento de informações.

Chiavenato (2003, p.128), em seu livro "Introdução à Teoria Geral da Administração", traz que "a comunicação é a troca de informações entre pessoas". Similarmente, Pimenta (2002) diz que a comunicação é a captação e o entendimento por parte de alguns indivíduos de uma mensagem emitida por um outro indivíduo.

A partir de tais conceitos, pode-se dizer que o processo de comunicação coexiste em "emissor, mensagem e receptor", ou conforme Melo (2006), na comunicação considerada como fonte de convívio social e humano encontra-se os seguintes elementos: "comunicador, mensagem e destinatário". O processo de comunicação envolve no mínimo duas pessoas/indivíduos ou grupos: remetente (fonte/emissor) e o destino (receptor).

O teor da comunicação é geralmente uma mensagem e o seu alvo é a compreensão por parte de quem a recebe. A comunicação só ocorre efetivamente quando o destino (quem a recebe) a compreende ou a interpreta. Logo, se a mensagem não chegou ao destino, a comunicação não aconteceu (MELO, 2006). Para Gil (2001) apud Silva e Júnior (2014), a comunicação 
também vai além do simples ato de informar, devendo existir um entrosamento entre as partes, emissor e receptor, para que a mensagem seja desenvolvida e tenha sentido para ambos, para que assim, haja então verdadeiramente uma comunicação entre os envolvidos.

Ruggiero (2002) foi além ao concluir que a comunicação só se torna efetiva quando são consideradas as vertentes da verdade e autenticidade. Caso contrário, o que acontecerá será perda de tempo e uma "anti-comunicação" em relação ao essencial e necessário. Garantir que a comunicação ocorra não é o bastante, é primordial que a ideia ou a mensagem seja realmente aprendida para que os receptores tenham capacidade de aplicá-la. Dessa maneira, nas organizações o trabalho em equipe deve ser incentivado através da cooperação e ajuda mútua, promovendo ações coletivas, evitando os afastamentos e as falhas na estimada comunicação.

\section{Comunicação Interna e seus Efeitos no Meio Corporativo}

Segundo Closs (2018) a comunicação interna é "um setor planejado, com objetivos definidos para possibilitar a interação entre organização e seus colaboradores. Com ela é possível aprimorar os relacionamentos e aumentar a produtividade, o engajamento e até mesmo os resultados financeiros de uma organização."

Para Melo (2006) a comunicação interna tem por objetivo tornar influentes, informados e integrados todos os membros de uma empresa além de possibilitar aos colaboradores o conhecimento das transformações ocorridas no ambiente de trabalho. A comunicação interna pode fazer com que os pontos fortes dos integrantes de determinada organização sejam aproveitados e atuantes no andamento dos negócios, facilitando assim a convivência harmoniosa da equipe e o alcance das metas da organização, permitindo uma comunicação cada vez mais natural e descomplicada.

Silva e Júnior (2014) completam que a comunicação interna é um instrumento estratégico, em que a mensagem é direcionada no momento oportuno, impulsionando o colaborador a atingir metas estabelecidas, criando sinergia entre os setores de forma que aumente o trabalho cooperativo, priorizando decisões rápidas e assertivas e organizando os métodos de trabalho para torná-los cada vez mais produtivos. Destacam que, a comunicação interna em sua essência tem o objetivo de envolver todos os colaboradores em prol de um bem comum, sendo que uma organização só obtém resultados, sucesso e 
deixa seu legado se todos os envolvidos estiverem movidos pelo mesmo desejo.

Neste sentido, Bueno (2000, p.50) cita:

\begin{abstract}
A comunicação empresarial evoluiu de seu estágio embrionário, em que se definia como mero acessório, para assumir, agora, uma função relevante na política negocial das empresas. Deixa, portanto, de ser atividade que se descarta ou se relega a segundo plano, em momentos de crise e de carência de recursos, para se firmar como insumo estratégico [...].
\end{abstract}

Ainda conforme Silva e Júnior (2014), hoje em dia não há mais o que omitir para os colaboradores de uma organização, considerando os avanços tecnológicos e a modernidade. A comunicação é essencial para qualquer organização e é necessário que a equipe esteja bem informada composta por integrantes que possuam boa interação entre eles, pois profissionais bem informados e integrados possuem um importante diferencial competitivo.

Expôs Matos (2009), de maneira muito realista, que a falta da cultura do diálogo, da abertura para troca de ideias, conversação, exposição de opiniões e sentimentos, talvez seja o maior gargalo enfrentado pelas empresas e que isso tem prejudicado fortemente o funcionamento de organizações e países. A comunicação corporativa é, categoricamente, um processo diretamente ligado à cultura da empresa ou organização, ou seja, aos valores e ao comportamento de suas lideranças e às convicções e perspectivas dos seus colaboradores.

Também é importante frisar segundo Bueno (2003), que a comunicação interna não deve se restringir apenas em informações que percorrem de cima para baixo na hierarquia empresarial, mas sim, e cada vez mais, de forma horizontal e ascendente. Uma boa comunicação organizacional interna é feita de forma descendente, ascendente e horizontalmente, pois até mesmo o conceito básico de comunicação já remete a uma via de mão dupla.

Conforme Vigneron (2000), somente nos anos 30 que as grandes organizações industriais iniciaram a preocupação com as relações humanas nas empresas. Antes disso, a mão de obra era considerada exclusivamente do ponto de vista técnico e mecanicista. A partir dessa época, nas grandes organizações iniciaram os processos de comunicação interna e suas correlações.

Desde então, para Closs (2018), a comunicação pode ser vista como um emaranhado de ações conduzidas por meio de canais para inteirar e engajar os colaboradores com a organização. É através da comunicação interna que os colaboradores têm conhecimento do que ocorre no dia a dia da organização, bem como os ideais e os valores da empresa. 
A necessidade de tornar os funcionários influentes, integrados e informados do que acontece na empresa, fazendo-os sentir parte dela, fez surgir a comunicação interna, considerada hoje como algo imprescindível às organizações, merecendo, cada vez mais, atenção especial em vista aos impactos positivos de sua aplicação (MELO, 2006).

Para Marchiori (2008), a comunicação interna oportuniza a troca de informações, contribuindo para a construção do conhecimento, o qual é expresso nas atitudes dos colaboradores. É fundamentalmente um processo que engloba a comunicação administrativa, fluxos, barreiras, redes formais e informais. Promove, portanto, a interação social e fomenta a credibilidade, agindo no sentido de manter viva a identidade de uma empresa.

\footnotetext{
A comunicação deve produzir conhecimento, definindo caminhos que levem a organização a um processo de modernização, na busca de sua percepção e consequentemente consciência comportamental. Sendo assim, a comunicação deve agir no sentido de construir e consolidar o futuro da organização. (MARCHIORI, 2006, p.27).
}

Assim como evidenciado pelos autores supramencionados, de forma extensiva a toda organização e meio corporativo, a comunicação dentro do ciclo de vida de um projeto de engenharia precisa elevar o seu nível de efetividade e constância, para que sejam garantidos o cumprimento das propostas e dos cronogramas físico-financeiros inerentes ao processo construtivo. Esses são grandes desafios para os gestores do projeto e só serão possíveis por meio da comunicação fluida, contínua e diligente: conhecer, contextualizar e alinhar toda a equipe de planejamento, controle, logística e produção em um só propósito, agregando força coletiva e visão holística aos seus colaboradores. Além disso, manter um discurso positivo e esclarecedor junto aos stakeholders (projetista, gestores, executor, clientes etc.) é vital para o bom andamento do projeto e crucial para sua conclusão e entrega do empreendimento com funcionalidade plena e desempenho satisfatório.

\subsection{Ferramentas e Canais de Comunicação}

De acordo com Marchiori (2008), várias são as abordagens de análise que demonstram características da comunicação, como informar, avaliar sobre o nível de entendimento de uma mensagem, readequar veículos e mídia, identificar o nível de informação, estudar formas de manter o público informado, analisar 
atitudes, avaliar estímulo/resposta entre emissor e receptor, mensurar o resultado dos processos de informação e comunicação.

Para Silva e Júnior (2014) os canais de comunicação da organização possuem funções essenciais para a efetividade da transmissão da mensagem. Tais canais devem estar disponíveis para serem meios capazes de registrar a mensagem e agir para a utilidade geral como reforço e eficácia dos programas de integração interna segurança e higiene, desenvolvimento organizacional, campanhas em geral e relações públicas externas.

Os desafios se encontram na definição dos canais de comunicação que serão utilizados na estratégia da organização. Existem diversas variáveis que devem ser levadas em consideração na escolha de um ou vários meios em que todos os colaboradores estejam ligados/conectados. Estudos apontam que a escolha dependerá do perfil dos colaboradores, estrutura física e organizacional da empresa, de quais são os recursos disponíveis, facilidade de familiarização com as ferramentas adotadas, disponibilidade, entre outros critérios. Estar ciente da capacidade do público interno e conhecer quais os caminhos para introdução da comunicação, poderá ser a garantia do sucesso no processo da comunicação interna (CLOSS, 2018).

As ferramentas para comunicação interna são variadas. Existem o Mural, Jornal ou Revista Corporativa, Vídeos, Intranet, entre outros. Para Jaques Vigneron (2000), comunicação não é tarefa só de peritos é assunto de todos os membros, de quem determina a política de comunicação até o chão de fábrica.

Nos dias atuais, com o avanço da tecnologia e crescimento econômico, as mudanças e atualizações de técnicas e ferramentas ocorrem extremamente rápidas e tais modificações refletem diretamente na forma de se comunicar. Para acompanhar os avanços e melhorias contínuas, as organizações incentivam a utilização de equipamentos eletrônicos onde a velocidade da transmissão da mensagem é instantânea, advento da internet, fazendo com que os colaboradores tenham acesso à informação em tempo real ou possam consultá-la sempre que houver necessidade ou disponibilidade.

Pesquisas realizadas pela Associação Brasileira de Comunicação Empresarial - ABERJE em conjunto com o Instituto ABERJE de Pesquisa DATABERJE (2012), apontam os veículos/meios mais utilizados na comunicação interna, sendo os "meios digitais" o principal veículo de Comunicação Interna para $50,6 \%$ das empresas participantes. A Intranet é responsável por 25,9\% da comunicação interna para as organizações pesquisadas, seguida pelos 
comunicados via e-mail com $16,3 \%$.

Embora os meios digitais façam sucesso atualmente, 36,7\% das empresas pesquisadas ainda utilizam os veículos tradicionais para comunicação interna, com destaque para o Jornal Mural com 14,5\%, Revista com 11,4\% e Jornal Impresso com 8,4\%. Um fator interessante da pesquisa é sobre a relação da definição do principal veículo da comunicação interna com o setor de atuação da organização. Observa-se que $57 \%$ das organizações dos segmentos de Comércio e Serviços utilizam meios digitais, enquanto $60 \%$ do segmento da Indústria faz uso dos meios tradicionais da comunicação interna.

Para a comunicação interna disponível e aplicada nas empresas, de forma geral, utilizam-se de uma grande variedade de veículos, conforme apresentado na figura 01.

Figura 1 - Veículos de "comunicação interna” disponíveis aos funcionários.

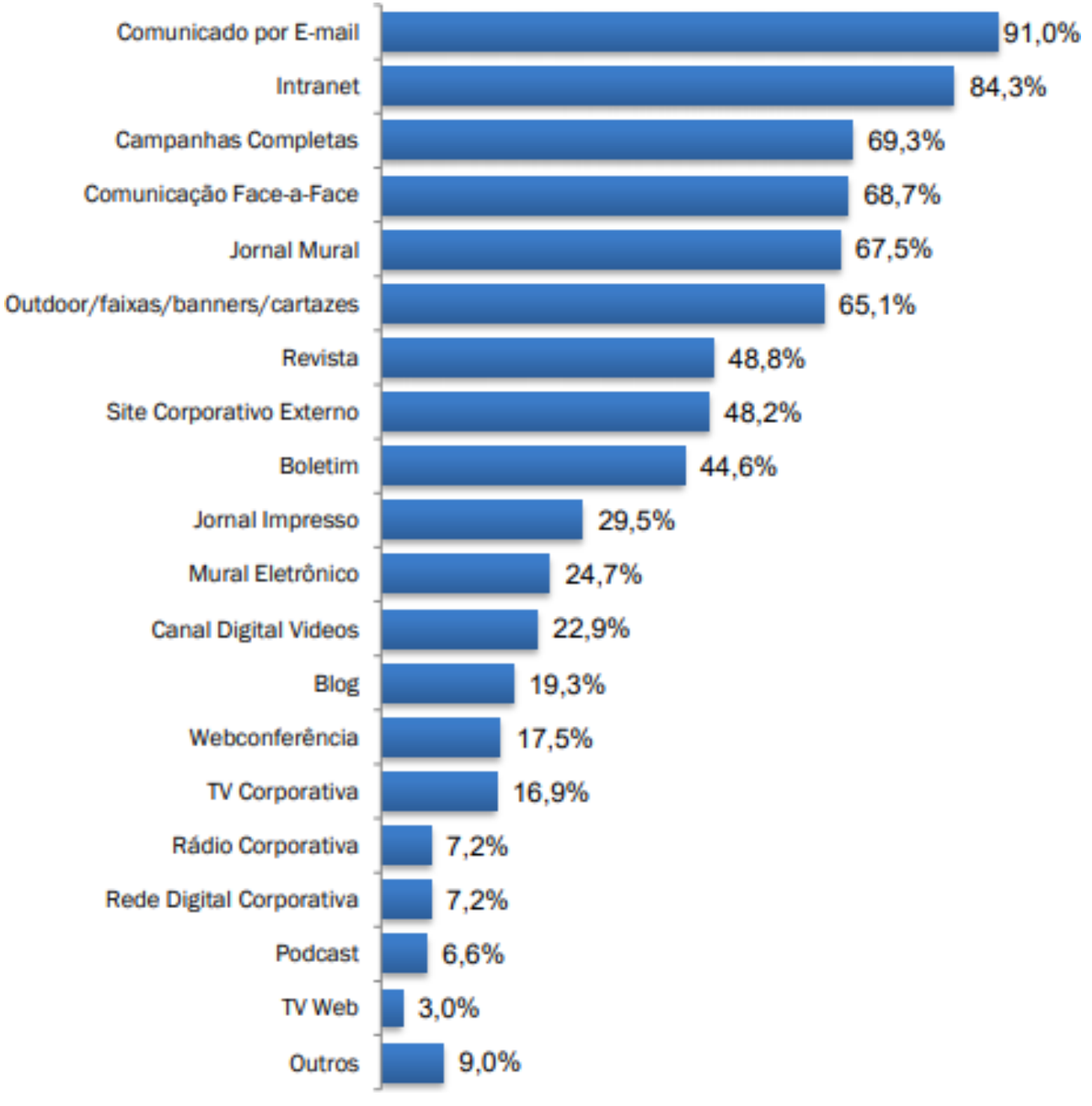

Empresarial, 2012.

Fonte: ABERJE - Associação Brasileira de Comunicação

Pode-se observar que dentre os veículos utilizados, três grandes blocos merecem destaque. O primeiro, com utilização massiva pela grande maioria das 
empresas está o "Comunicado por E-mail" com 91,0\%, seguido pela "Intranet" com $84,3 \%$. Em segundo lugar, representando cerca de $60 \%$ das empresas, está a realização de "Campanhas Completas" com 69,3\%, "Comunicação Facea-Face" com 68,7\%, "Jornal Mural" com 67,5\% e "Outdoors e Faixas" com $65,1 \%$. Por último, e com até $50,0 \%$ de utilização pelas empresas estão a "Revista" com 48,8\%, "Site Corporativo" com 48,2\% e os "Boletins" com 44,6\%.

Em posse desses dados depreende-se que os veículos digitais e tecnológicos estão conquistando cada vez mais espaço na utilização pelas empresas, em razão da facilidade e velocidade de transmissão, baixo custo e com um alcance de grandes públicos.

\section{Ciclo de Vida de um Projeto de Engenharia}

O guia Project Management Body of Knowledge (PMBOK) é um conjunto de práticas na gestão de projetos organizado pelo instituto $\mathrm{PMI}$ e é considerado a base do conhecimento sobre gestão de projetos por profissionais da área. Segundo o guia Project Management Body of Knowledge - PMBOK (2008) o projeto é um esforço temporário empreendido para criar um produto, serviço ou resultado exclusivo, com um propósito de desenvolver uma solução dentro de parâmetros bem delineados. O objetivo de um projeto é alcançar as metas previamente definidas, sendo todas as partes envolvidas responsáveis por conduzi-lo rumo a concretização dos objetivos almejados. Assim, pode-se inferir que qualquer projeto possui três características em comum: particularidade, pois as condições, recursos e envolvidos são únicos; temporariedade, pois tem duração e recursos limitados; e progressividade, pois tem início, meio e fim definidos.

Ainda para o PMBOK, as etapas do ciclo de vida de um projeto são comumente divididas em cinco: Iniciação, Planejamento, Execução, Monitoramento e Controle e por fim o Encerramento - IPEME.

A Iniciação é a fase na qual ocorre a identificação da necessidade em questão. Nessa etapa, os objetivos do projeto são definidos e estruturados para serem atacados de maneira assertiva.

O Planejamento será a etapa em que haverá a definição da metodologia a ser empregada para a gestão dos projetos. É nessa etapa em que as estratégias são traçadas considerando os recursos mobilizados e os objetivos a serem atingidos. Durante o planejamento é realizada a previsão de recurso, o dimensionamento de custos e pessoal, definição das competências e elaboração do cronograma.

$\mathrm{Na}$ etapa da Execução é onde tudo ocorre, ou seja, o planejamento é colocado em prática. Através da execução do que foi planejado, qualquer equívoco no momento de planejar é evidenciado e para aferir os detalhes, o tempo demandado, a qualidade 
executiva, o Monitoramento e Controle entra em prática. Nessa etapa, todo o procedimento executivo será aferido, diagnosticando falhas na concepção do projeto na iniciação, falhas de planejamento e execução. Ou seja, a etapa do Monitoramento e Controle percorre por todo o ciclo de vida do projeto.

Logo após a quarta etapa, o Encerramento acontece com a entrega do produto desenvolvido. Assim, evidencia-se que as etapas não são individualizadas, ou seja, estão intimamente ligadas umas às outras como pode-se verificar na figura 02.

Figura 2 - Ciclo de Vida de um Projeto.

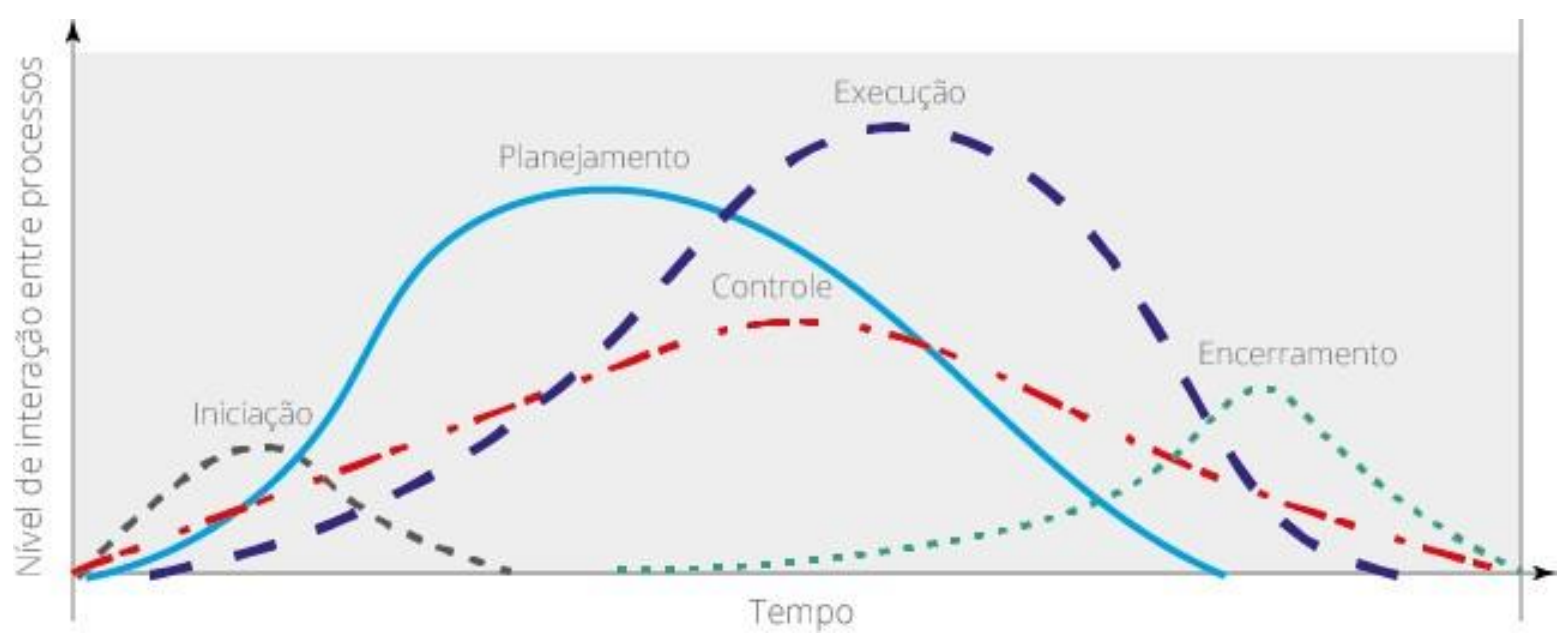

Fonte:

Artia, 2019.

Através da análise da Figura 02, nota-se que as etapas de ciclo de vida de um projeto estão interligadas e sobrepondo umas sobre as outras. Levando em consideração essa sobreposição, depreende-se que há entre uma etapa e outra, o diálogo recorrente dos stakeholders, ou seja, a comunicação entre as partes interessadas. Daí surge a necessidade de uma comunicação limpa e objetiva, sem ruídos ou falhas, uma vez que haverá uma transição de responsabilidades e metas a serem cumpridas. Perfazendo uma analogia, o ciclo de vida de um projeto de engenharia é uma espécie de corrida com passagem de bastão, em que se a passagem não acontecer de forma precisa, todo o trabalho desempenhado pelas equipes das etapas predecessoras, será em vão e de nada valerá todo esforço empregado.

Os profissionais que estão empenhados na etapa de iniciação deverão transmitir as mensagens para os profissionais que seguirão com a condução do projeto na etapa de planejamento, e assim por diante. $\mathrm{Na}$ etapa de planejamento, os indivíduos deverão se comunicar entre si para elaborar as melhores estratégias para uma execução bem conduzida. Iniciada a etapa da Execução, há ainda interferências do Planejamento, ou seja, a comunicação entre essas etapas deve ser a mais eficiente possível, uma vez que a 
construção já está em andamento. E, uma comunicação malconduzida, pode acarretar em interferências e erros que gerarão retrabalhos no futuro.

Através da figura 02, percebe-se que a etapa do Monitoramento e Controle ocorre ainda na Iniciação e percorre por todo ciclo de vida do projeto. Essa etapa é relevante pois é a que está ligada a todas as outras de maneira contínua e simultânea. É ela a responsável pela boa condução daquele projeto, pela interligação e comunicação com excelência entre todas as outras etapas.

Ainda durante a execução, dá-se o início da última etapa denominada Encerramento. Esta etapa é a que os envolvidos finalizam as atividades de todos os grupos de processos e, além disso, formaliza a entrega do projeto com todos os documentos pertinentes.

Além da comunicação interna entre os envolvidos diretos na execução do projeto, a comunicação com o cliente (contratante) deve ser tratada de forma especial e diligente, uma vez que ele é o maior interessado no produto final, pois dará em sequência o uso e ocupação ao empreendimento. Dessa forma, quaisquer esclarecimentos sobre o escopo do projeto e detalhes executivos devem, invariavelmente, serem tratados anteriormente à execução propriamente dita, a fim de evitar retrabalhos e consequentemente o aumento do custo da obra. Conhecer todas as exigências do contratante e entender as suas necessidades preliminarmente, torna o processo de execução mais assertivo, competente, com qualidade satisfatória e dentro do prazo estimado para sua conclusão, respeitando dessa forma a tríplice restrição de um projeto: escopo, tempo e custo.

\section{Metodologia}

A elaboração deste artigo científico fora embasada em uma pesquisa bibliográfica de caráter exploratória a partir de livros, dissertações, teses, artigos e sites específicos relacionados ao conteúdo elucidado, bem como pesquisa complementar em empresas locais sobre as metodologias e ferramentas utilizadas na área relacionada a este artigo, a fim de que o observado na literatura fosse também assistido no dia a dia organizacional, e novas fontes de pesquisa fossem incentivadas.

Tal evento vislumbra a comparação de tais metodologias e ferramentas de comunicação almejando estabelecer qual delas tem maior efetividade antes suas proposições, e por conseguinte, menor impacto financeiro aliado ao ganho de 
contextualização, aplicabilidade e tempo durante o ciclo de vida do projeto.

É sabido da particularidade e singularidade de cada projeto, e necessário se faz o estabelecimento e adequação para cada ocasião, rumo aos objetivos organizacionais assertivos.

\section{Resultados e Discussão}

\subsection{Estudo de Caso de Empresas Locais}

Foi elaborado um estudo de caso comparando a metodologia de comunicação empregada em duas empresas de engenharia da cidade de Teófilo Otoni - Minas Gerais. As identidades das empresas não foram reveladas e então serão denominadas de empresa " $X$ " e empresa " $Y$ ". Apesar da diferença de porte entre as empresas, o que foi elucidado no estudo está relacionado à metodologia empregada na comunicação dentro do ciclo de vida do projeto.

Dessa maneira, foram abordados cinco tópicos em que a comunicação efetiva foi empregada sendo eles:

I. Comunicação com o cliente;

II. Comunicação no canteiro de obras;

III. Comunicação no ambiente de suporte à produção;

IV . Comunicação entre suporte à produção e canteiro de obras;

V. Comunicação com fornecedores.

\subsubsection{Comunicação com o cliente}

A comunicação com o cliente representa uma etapa do ciclo de vida do projeto em que poderá potencializar ainda mais os resultados quando bem-feita. Aquela, representa um verdadeiro diferencial para 0 sucesso do empreendimento e quando executada de forma clara, objetiva e eficiente gera rapidez e qualidade durante a execução.

Com o escopo bem definido e a compatibilização bem executada, a comunicação com o cliente se resumirá em apenas informações de como está o processo da execução do projeto.

A empresa " $X$ " adota uma forma de comunicação presencial, com a marcação de reuniões e/ou encontros formais para tratar sobre o andamento físico e financeiro do projeto. Em um primeiro momento a marcação da reunião acontece através de uma ligação telefônica ou envio de mensagem via aplicativo 
de celular. Após, em comum acordo, marca-se o local da reunião para apresentação dos dados da execução e acontece então o encontro interpessoal com interação e troca de informações. Na grande maioria dos casos, a reunião acontece no próprio canteiro de obras, em que o cliente tem a oportunidade de visualizar e conferir, com o acompanhamento do profissional técnico responsável, o que de fato foi executado entre uma reunião e outra que não tem prazo definido, podendo acontecer vários encontros em um só mês.

Por outro lado, a empresa "Y" adota a troca de informações com o cliente de forma virtual, através de envio e recebimento de e-mails com fotos do avanço físico. O deslocamento do cliente até o canteiro acontece eventualmente, a cada mês e o acompanhamento do avanço físico acontece de forma remota.

\subsubsection{Comunicação no canteiro de obras}

A comunicação no canteiro de obras deve ser a mais transparente, direta e clara possível. É onde o projeto está ganhando forma, onde os envolvidos estão empenhados e engajados em um só propósito. As consequências por falta de comunicação são imensuráveis, tais como o retrabalho e a execução de atividades não prioritárias, por exemplo. E além disso, a falta de uma boa comunicação pode interferir na produtividade e segurança no trabalho. Assim, saber como otimizar a comunicação colaborará para reduzir e até mesmo anular os retrabalhos tendo como consequência processos mais eficientes e seguros.

Então, várias são as formas que a comunicação acontece no canteiro. Dentre as mais empregadas, existem a sinalização de alerta de perigos e atenção através da instalação de placas em lugares estratégicos; lembranças da necessidade de uso de Equipamento de Proteção Individual e Equipamentos de Proteção Coletiva; placas com a identificação dos profissionais capacitados para operação de determinados equipamentos entre outros. Existem ainda empresas que criam seu próprio sistema de TV Corporativa para transmissão de informações sobre $o$ andamento da obra, treinamentos de capacitação profissional, reforçar normas e relembrar prazos.

Embasados nessas metodologias de comunicação, a empresa " $X$ " adota a instalação de placas em pontos estratégicos no canteiro bem como reuniões diárias entre os colaboradores a fim de direcionar cada um deles a determinada atividade.

Já a empresa "Y" possui seu sistema de TV Corporativa com vídeos gravados pelos próprios colaboradores alertando e instruindo sobre a importância 
do engajamento na execução do projeto. Ainda utilizam placas de identificação por todo canteiro em pontos estratégicos além de reuniões diárias para distribuição de equipes de trabalho e demonstração da importância de cada colaborador durante a execução.

\subsubsection{Comunicação no ambiente de suporte à produção}

No escritório de engenharia é onde acontece toda a concepção, planejamento e compatibilização dos projetos para uma execução visando a minimização dos efeitos negativos pela tomada de decisões de forma incorreta. A troca de informações nessas etapas organiza as tarefas priorizando as ações mais relevantes no momento direcionando toda a equipe de acordo com os objetivos propostos. Assim, o estabelecimento de um sistema de comunicação eficiente é mais relevante do que ter engenheiros e gerentes passando as informações para a equipe de campo, mas também é uma forma de criar diálogos entre os diferentes setores.

Na empresa " $X$ ", as informações no escritório são veiculadas através de conversações interpessoais com vistas a um só objetivo. Acontece ainda troca de mensagens através de aplicativos de celular sempre quando um colaborador não está presente no escritório.

Já na empresa "Y", é comum a troca de mensagens através de aplicativos de conversação, apesar de haver constantemente reuniões para debates sobre metodologias executivas, determinação de escopo, direcionamento de equipes de gestores. Ainda na empresa "Y", existe a troca de ofícios e relatórios entre os setores para contextualização de todos os envolvidos.

\subsubsection{Comunicação entre suporte à produção e canteiro de obras}

Estamos aqui em um ponto de extrema atenção no quesito comunicação, pois é aqui onde ocorre toda a transferência de informações entre o escritório e o canteiro de obras. Portanto, estabelecer formas de contato é de grande valia para que todos estejam alinhados com o trabalho, cronograma e prazos. Além disso, é uma forma de receber sugestões e ouvir o que os trabalhadores têm a dizer sobre o serviço.

Na empresa "X", a comunicação entre o suporte à produção e o canteiro de obras é feita de forma presencial, com visitas ao canteiro rotineiramente. Somente em casos em que o canteiro não se encontra na mesma cidade é que a comunicação é realizada através de contato telefônico e envio de mensagem 
através de aplicativos, embora ainda ocorra a visita mensal de um responsável técnico do escritório no canteiro.

Na empresa "Y", essa comunicação é realizada de forma remota através de trocas de mensagens via aplicativos, através de contato telefônico e ainda por meio de vídeos conferências. As trocas de mensagens via aplicativos é realizada através de grupos característicos das obras de forma projetizada em que todos os envolvidos diretos fazem parte do grupo e estão antenados a toda e qualquer modificação que aconteça. Esporadicamente é realizada uma visita ao canteiro de obras, haja vistas que a grande maioria dos canteiros não se encontram na cidade de Teófilo Otoni, dificultando o acesso rápido.

\subsubsection{Comunicação com fornecedores}

Em projetos de engenharia, contar com bons fornecedores é essencial para o desenvolvimento e execução do projeto visando a garantia de sucesso e satisfação do cliente. Os fornecedores são os principais parceiros no processo e ter problemas na relação ou na comunicação poderá impactar significativamente no produto final, atrasando cronogramas ou não atendendo as expectativas.

Para que a relação e comunicação com os fornecedores seja transformada em parceria, é necessário que haja transparência deixando claras as expectativas quanto ao que se espera de determinado produto ou serviço; transparência nas condições do contrato; manter os processos alinhados através de reuniões; manter uma conversação clara sobre falhas e acertos; dividir com o fornecedor o sucesso; trata-lo como parte integrante da equipe e principalmente estabelecer um fluxo de comunicação deixando claro quem são as pessoas chave no processo e de que forma os canais de comunicação deverão ser usados.

Na empresa "X", a comunicação com os fornecedores é realizada em um primeiro momento através de contato telefônico e posterior visita ou no escritório de engenharia ou no escritório do fornecedor. Após, a comunicação é realizada por telefone com eventuais visitas a fim de manter o bom relacionamento e parceria duradoura.

Já na empresa "Y", o contato com os fornecedores acontece de forma remota, através de ligações, trocas de mensagem e e-mails, já que a grande maioria dos mesmos não se encontram em locais próximos ao escritório. Além disso são realizadas eventuais visitas ao escritório de engenharia bem como visitas aos canteiros de obras. 


\section{Análise do Estudo de Caso sobre o comparativo entre as Empresas " $X$ " e "Y"}

Com base nas informações do estudo de caso em que foi explanada as metodologias de comunicação das duas empresas na cidade de Teófilo Otoni Minas Gerais, percebe-se que ambas empresas se moldam de acordo com as estratégias que mais Ihes facilitam ou viabilizam o andamento do projeto.

No quesito de comunicação com o cliente a empresa " $X$ " se sobressai em detrimento a " $Y$ " por haver mais encontros interpessoais, haver mais "calor" na relação entre contratante e contratada.

Para o quesito comunicação no canteiro de obras a empresa " $\mathrm{Y}$ " tem melhor desenvoltura com a utilização de tecnologias que favorecem e aceleram a comunicação, além de estar diariamente alertando sobre a preocupação com o colaborador. Já a empresa "X", não se preocupa da mesma forma que a empresa "Y" nesse quesito.

A comunicação no ambiente de suporte à produção, para as duas empresas, tanto a " $X$ " quanto a " $Y$ " se equivalem nesse aspecto.

Já na comunicação entre suporte a produção e canteiro de obras, a empresa " $X$ ", apesar de usar menos a tecnologia nesse quesito, tem maior eficiência, pois a presença no canteiro de obras de um representante do escritório para trocar informações diariamente faz com que estreite a lacuna que por vezes aparece entre equipe operária e equipe de escritório. A empresa " $Y$ " abusa da tecnologia nesse quesito, porém é insuficiente no contato humano e estreitamento das relações.

Em relção à comunicação com os fornecedores as duas empresas equiparam, sendo essa relação de parceria de forma duradoura e consistente.

Apesar das dificuldades no cenário econômico do país e em virtude disso, cada empresa deve se adaptar sempre em busca da viabilização do projeto.

Em ambas pode-se perceber que a utilização da tecnologia vem sendo amplamente difundida. Tal metodologia visa a economia, rapidez e precisão na transmissão da mensagem e ainda conta com o envio de imagens e vídeos.

\section{Considerações Finais}

Para Melo (2006), o estudo da comunicação interna nas organizações é um processo complexo, porém necessário a fim de afastar insatisfações e descontentamentos no ambiente de trabalho. Dessa forma, com a utilização das 
inúmeras ferramentas e com o auxílio da tecnologia, o processo se tornará mais eficiente e sem barreiras.

Com o estudo de caso abordado nesse trabalho, pode-se perceber o quão importante é a comunicação simples, limpa e eficiente. Os aspectos abordados e as metodologias empregadas visam sempre a busca da eficiência e clareza na transmissão da mensagem e na interação entre os colaboradores. Assim, a área da comunicação passa a ser altamente estratégica para as organizações, deixando de ser apenas meramente função tática.

A comunicação tem papel fundamental no cumprimento da missão e fixação dos valores das empresas do setor da engenharia civil. É importante ressaltar que a conquista dos objetivos, o atingir das metas e o cumprir dos cronogramas estabelecidos estão intimamente ligados à comunicação eficiente.

Sem tratar a comunicação como realmente deve ser tratada, com toda a importância em prol de um só objetivo e bem estar da empresa, a construção de um sonho para muitos clientes passará a ser uma verdadeira frustração, pois sem o entendimento do que se deseja com o que deve ser empregado e executado, a construção se tornará uma verdadeira "Torre de Babel".

\section{Referências}

BUENO. W. C. A Comunicação como o espelho das culturas empresariais.

Revista Imes - Comunicação, ano I, № 1, jul/dez 2000.

2003.

Comunicação empresarial: teoria e pesquisa. Barueri: Editora Manole,

CHIAVENATO, I. Introdução à teoria geral da administração: uma visão abrangente da moderna administração das organizações. 7 ed. Rio de Janeiro: Elsevier, 2003.

CLOSS, D. Comunicação Interna: Tudo que você precisa saber para melhorar a da sua Empresa. Progic, São Paulo, 2018. Disponível em: $<$ https://endomarketing.tv/comunicacao- interna/\#.XlcpNShKjIW>. Acesso em: 26 fev. 2019

ESPINHA, R. G. Ciclo de Vida de Projetos. Artia. Joinville, SC. 2019.

Disponível em:

$<$ https://artia.com/blog/ciclo-de-vida-de-projetos/>. Acesso em: 06 abr. 2019.

GIL, A. C. Gestão de pessoas: enfoque nos papéis profissionais. São Paulo: Atlas, 2001. MARCHIORI, M. Comunicação interna: um olhar mais amplo no contexto das organizações.

Universidade Estadual de Londrina, Londrina, PR, 2008. Disponível

em:<https://www.researchgate.net/profile/Marlene_Marchiori/publication/2620487 47_Comun

icacion_interna_una_vision_mas_amplia_en_el_contexto_de_las_organizacione 
s/links/54f48 70c0cf2f28c1361cfa6.pdf>. Acesso em: 05 mar. 2019.

Cultura e Comunicação organizacional: um olhar estratégico sobre a organização. São Caetano/SP: Difusão editora, 2006.

MATOS, G. G. Comunicação Empresarial sem complicação: como facilitar a comunicação na empresa, pela via da cultura e do diálogo. $2^{a}$ Edição Revisada e Atualizada. Barueri, SP. Manole, 2009.

MELO, V. P. C. A comunicação interna e sua importância nas organizações. Academica.edu, Vitória da Conquista, 2006.

Disponível em:

$<$ https://s3.amazonaws.com/academia.edu.documents/34001870/A-

comunicacao-interna-e- sua-importancia-nas-organizacoes-Vanessa-Pontes-

Chaves-de-

Melo.pdf?AWSAccessKeyld=AKIAIWOWYYGZ2Y53UL3A\&Expires $=155931530$

8\&Signa ture=JlyJ\%2ByP0z2R4dg5HrxV709YRitU\%3D\&response-content-

disposition=inline\%3B\%20filename\%3DA-comunicacao-interna-e-sua-

importancia-.pdf>. Acesso em: 25 fev. 2019

NASSAR, P.; RAMELLO, C. A.; COGO, R. 4a Pesquisa comunicação interna 2012: dados comparativos 2005, 2007, 2012. Associação Brasileira de Comunicação Empresarial. São Paulo: ABERJE,2012.

Disponível em:

<http://www.aberje.siteprofissional.com/acervo_pesquisas.asp>. Acesso em: 16 mar. 2019.

PIMENTA, M. A. Comunicação Empresarial. 3 ed. Campinas/SP: Editora Alínea, 2002.

PMBOK, GUIA. Um guia do conjunto de conhecimentos em gerenciamento de projetos (guia pmbok ${ }^{\circledR}$ ). em português. Project Management Institute, Inc. EUA, 2008.

RUGGIERO, A. P. Qualidade da comunicação interna. RH. São Paulo. out. 2002. Disponível em: < http://www.rh.com.br/Portal/imprima.php?cod=3388>. Acesso em 07 mar. 2019.

SILVA, K. F.; JÚNIOR, R.M. Comunicação Interna e sua Importância nas Organizações: Case Petrobras. UNOESTE, Presidente Prudente, 2014. Disponível em:

<http://www.unoeste.br/site/enepe/2014/suplementos/area/Humanarum/Comunic a\%C3\%A7\%C3\%A3o/Comunica\%C3\%A7\%C3\%A30\%20Interna\%20e\%20sua\% $20 \mathrm{import} \% \mathrm{C} 3 \% \mathrm{~A} 2$ ncia\%20nas\%20organiza\%C3\%A7\%C3\%B5es.pdf>. Acesso em: 20 mar. 2019.

VIGNERON, J. Comunicação Interna além das mídias. 60 Seminário de Comunicação do Banco do Brasil,Rio deJaneiro, RJ,2000. Disponível em: <https://www.academia.edu/24909117/COMUNICA\%C3\%87\%C3\%830_INTER NA_AL\% C3\%89M_DAS_M\%C3\%8DDIAS>. Acesso em: 06 mar. 2019. 